\title{
Editorial Communication
}

\section{RETRACTED}

\section{POST-ANTHESIS CHANGES IN CHLOROPHYLL AND AGRONOMIC TRAITS OF BREAD WHEAT GENOTYPES}

This article has been retracted by the Editorial Board of Applied Ecology and Environmental

Research, with the agreement of the author. 